\title{
Corticotropin-releasing factor: innocent until proven guilty
}

\author{
William J. Giardino and Andrey E. Ryabinin
}

The recent Review article by Heilig et al. (Pharmacogenetic approaches to the treatment of alcohol addiction. Nature Rev. Neurosci. 12, 670-684 (2011)) $)^{1}$ expertly discussed strategies towards the development of therapeutics for alcoholism. However, we noticed a serious omission in their discussion of the corticotropin-releasing factor (CRF) system.

The authors described evidence supporting a role for CRF receptor $1\left(\mathrm{CRF}_{1}\right)$ in alcohol-related behavioural traits, concluding that phenotypic screening may improve the clinical efficacy of $\mathrm{CRF}_{1}$ antagonists. However, they did not acknowledge that in addition to $\mathrm{CRF}$ and $\mathrm{CRF}_{1}$, this system includes three CRF-related ligands (the urocortins (UCNs): $\mathrm{UCN}_{1}, \mathrm{UCN}_{2}$ and $\mathrm{UCN}_{3}$ ), an additional receptor $\left(\mathrm{CRF}_{2}\right)$ and the $\mathrm{CRF}$ binding protein $\left(\mathrm{CRF}_{\mathrm{BP}}\right)^{2}$. $\mathrm{UCN}_{2}$ and $\mathrm{UCN}_{3}$ bind $\mathrm{CRF}_{2}$ selectively, whereas UCN 1 binds both CRF receptors and the $\mathrm{CRF}_{\mathrm{BP}}$ with greater affinities than does CRF itself ${ }^{2}$ (FIG. 1).

Although such information might be considered extraneous, we would like to correct a mistake in the authors' Review ${ }^{1}$ that highlights precisely why it is necessary to acknowledge all

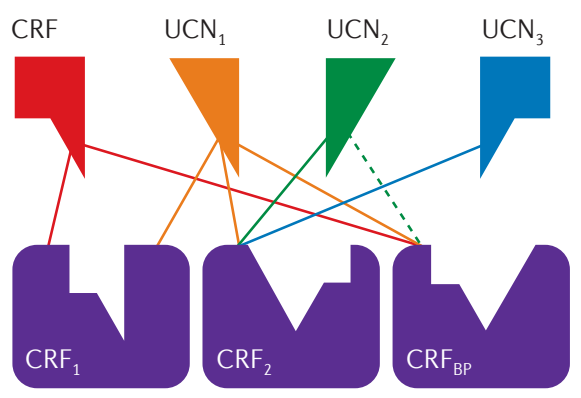

Figure 1 | Relationships among corticotropinreleasing factor (CRF), urocortins and their targets. CRF has high affinity for CRF receptor 1 $\left(\mathrm{CRF}_{1}\right)$ and $\mathrm{CRF}$ binding protein $\left(\mathrm{CRF}_{\mathrm{BP}}\right)$, urocortin $2\left(\mathrm{UCN}_{2}\right)$ and $\mathrm{UCN}_{3}$ are selective for $\mathrm{CRF}$ receptor $2\left(\mathrm{CRF}_{2}\right)$, and $U C \mathrm{~N}_{1}$ has high affinity for both receptors and the $C_{R F}$. Solid lines indicate high-affinity binding, dashed lines indicate species-dependent affinity.
CRF system components. Heilig et al. claimed that "blockade of stress-induced relapse is in part mediated by $\mathrm{CRF}_{1}$ blockade in the median raphe nucleus (MRN)", citing a 2002 study $^{3}$. In fact, those experiments used the non-selective ${ }^{4}$ antagonist $\mathrm{D}$-Phe $\mathrm{CRF}_{12-41}$, leaving in question whether this effect was mediated by $\mathrm{CRF}_{1}$ or $\mathrm{CRF}_{2}$. On the surface, the error appears to be minor. However, because the authors neglected to mention all CRF system components, they not only falsely implicated $\mathrm{CRF}_{1}$, but also implied that the underlying ligand must be CRF.

This example illustrates a broader problem in the literature. Our analysis of the most recent 120 items retrieved by a PubMed search for CRF (or CRH) system involvement in alcoholism or addiction (excluding articles that focused solely on the hypothalamic-pituitary-adrenal axis) found that only $34.7 \%$ of these articles acknowledged UCN peptides. Furthermore, $53.3 \%$ of these articles implied a role for CRF without providing evidence against a role for UCNs.

We also identified several cases in which authors applied a ligand exogenously and inferred that the same ligand must mediate the effect endogenously. For example, the 2002 study discussed above found that intra-MRN CRF infusions reinstated alcohol-seeking, and the authors inferred that this mechanism mediated alcohol-seeking endogenously ${ }^{3}$. We should point out that many brain areas receive co-innervation by multiple ligands of the CRF system ${ }^{2,5,6}$, complicating this interpretation.

Heilig et al. probably excluded $\mathrm{CRF}_{2}$ and urocortins because orally available $\mathrm{CRF}_{2}$ specific drugs do not exist. However, we might argue that the slower development of $\mathrm{CRF}_{2}$ targeted therapies is a by-product of the issues outlined above. In fact, $\mathrm{CRF}_{2}$-selective agonists are potent inhibitors of alcohol intake ${ }^{7,8}$, and their therapeutic potential has been discussed 9 . Aside from the authors' exclusion of $\mathrm{CRF}_{2}$, we remind them that $\mathrm{UCN}_{1}$ also exhibits high affinity for $\mathrm{CRF}_{1}$. Furthermore, genetic deletion of $\mathrm{UCN}_{1}$ dampened alcohol preference and alcohol-induced reward ${ }^{10}$, justifying the inclusion of UCNs in future conversation.

It is not our intent to diminish the role of CRF in alcohol-related behavioural traits. Rather, we hope that investigators will give careful thought to the endogenous mechanisms by which the CRF system influences behaviour and consider all suspects in order to generate a nuanced dissection of CRF system involvement in stress- and addictionrelated disorders.

William J. Giardino and Andrey E. Ryabinin are at the Department of Behavioural Neuroscience, Oregon Health and Science University, 3181 SW Sam Jackson Park Road, Portland, Oregon 97219, USA.

Correspondence to A.E.R. e-mail: ryabinin@ohsu.edu doi:10.1038/nrn3110-c1

Heilig, M., Goldman, D., Berrettini, W. \& O’Brien, C. P. Pharmacogenetic approaches to the treatment of alcohol addiction. Nature Rev. Neurosci. 12, 670-684 (2011).

2. Reul, J. M. \& Holsboer, F. Corticotropin-releasing factor receptors 1 and 2 in anxiety and depression. Curr. Opin. Pharmacol. 2, 23-33 (2002).

3. Le, A. D., Harding, S., Juzytsch, W., Fletcher, P. J. \& Shaham, Y. The role of corticotropin-releasing factor in the median raphe nucleus in relapse to alcohol. J. Neurosci. 22, 7844-7849 (2002).

4. Perrin, M. H., Sutton, S. W., Cervini, L. A., Rivier, J. E. \& Vale, W. W. Comparison of an agonist, urocortin, and an antagonist, astressin, as radioligands for characterization of corticotropin-releasing factor receptors. J. Pharmacol. Exp. Ther. 288, 729-734 (1999).

5. Bittencourt, J. C. et al. Urocortin expression in rat brain: evidence against a pervasive relationship of urocortin-containing projections with targets bearing type 2 CRF receptors. J. Comp. Neurol. 415, 285-312 (1999).

6. Deussing, J. M. et al. Urocortin 3 modulates social discrimination abilities via corticotropin-releasing hormone receptor type 2. J. Neurosci. 30 9103-9116 (2010)

7. Sharpe, A. L. \& Phillips, T. J. Central urocortin 3 administration decreases limited-access ethanol intake in nondependent mice. Behav. Pharmacol. 20, 346-351 (2009)

8. Funk, C. K. \& Koob, G. F. A CRF 2 agonist administered into the central nucleus of the amygdala decreases ethanol self-administration in ethanoldependent rats. Brain Res. 1155, 172-178 (2007).

9. Lowery, E. G. \& Thiele, T. E. Pre-clinical evidence that corticotropin-releasing factor (CRF) receptor antagonists are promising targets for pharmacological treatment of alcoholism. CNS Neurol. Disord. Drug Targets 9, 77-86 (2010)

10. Giardino, W. J., Cocking, D. L., Kaur, S., Cunningham, C. L. \& Ryabinin, A. E. Urocortin-1 within the centrallyprojecting Edinger-Westphal nucleus is critical for ethanol preference. PLoS ONE 6, e26997 (2011).

\section{Acknowledgements}

Authors are supported by US National Institutes of Health grants F31 AA021023 (W.J.G.) and AA013738, AA016647, AA010760 (A.E.R.)

Competing interests statement

The authors declare no competing financial interests.

\section{FURTHER INFORMATION}

Andrey Ryabinin's homepage: http://tinyURL.com/RyabininLab

ALL LINKS ARE ACTIVE IN THE ONLINE PDF 